\title{
Assessment of heavy metals and rheological characteristics of coal ash samples in presence of some selective additives
}

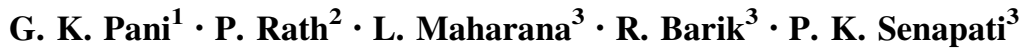

Received: 6 April 2015/Revised: 9 September 2015/Accepted: 13 September 2015/Published online: 28 September 2015

(C) Islamic Azad University (IAU) 2015

\begin{abstract}
The huge quantity of coal ash produced in Indian thermal power plants is disposed of in ash landfills or ash ponds. The deposition of ash in ash ponds through conventional lean slurry form is viewed as a major potential release of many environmentally sensitive heavy metals due to possible contamination with ground water. An attempt has been made in this paper to assess the leachability of the heavy metals such as $\mathrm{Cu}, \mathrm{Pb}, \mathrm{Ni}, \mathrm{Co}, \mathrm{Zn}$, $\mathrm{Cd}, \mathrm{Hg}$ and As from two Indian power plant ash samples in the presence of some selective low-cost additives. The additives used for the study were sodium silicate $\left(\mathrm{Na}_{2}\right.$ $\mathrm{SiO}_{3} \cdot 5 \mathrm{H}_{2} \mathrm{O}$ ), Reetha fruit (botanical name: Sapindus Mukorossi) extract, banana leaf extract, Aloe vera juice and active carbon. By adopting short duration (7 days) batch leaching test and toxicity characteristics leaching procedure (TCLP), the behaviour of various heavy metal ions released in water influenced by small dosage of these selective additives has been analysed. By introducing the same additives, the rheological behaviour of the two fly ash samples at high solids concentration $\left(C_{\mathrm{W}}=55-67.5 \%\right.$ by weight) was carried out using a HAAKE rotational rheometer (model: RheoStress 1, Thermo Fisher Scientific). The influence of small dosage of these additives on rheological parameters of the ash-water slurry has been discussed.
\end{abstract}

\footnotetext{
P. K. Senapati

pksenapati@immt.res.in

KIIT University, Bhubaneswar, India

2 School of Applied Sciences, KIIT University, Bhubaneswar, India

3 CSIR-Institute of Minerals and Materials Technology, Bhubaneswar, India
}

Keywords Fly ash · Leaching - Heavy metals . Rheology · Plastic viscosity

\section{Introduction}

At present, Indian thermal power plants generate around 200 million tones of coal ash, and major portion of these wastes are disposed of in ash landfills or ash ponds. The conventional dilute phase of ash slurry transportation system being practiced by the power plants causes leaching of heavy metals from the ash matrix in the ash ponds/dykes. The presence of these potentially toxic elements such as arsenic, cadmium, cobalt, lead, mercury, nickel and zinc can be considered hazardous for living organisms as they have tendency to leach out from fly ash at the disposal sites and contaminate the environment, especially surface and ground water (Sushil and Batra 2006; Senapati et al. 2012; Singh et al. 2014; Lokeshappa et al. 2014; Chen et al. 2014; Kosson et al. 2014; Rind et al. 2014; Krgovic et al. 2015). The assessment of leaching behaviour of fly ash may be performed thoroughly prior to selection of appropriate disposal method for its adequate management (Dawle et al. 2014). Experimental investigation on stabilization/solidification of iron ore mine tailings with cost-effective composite binders using cement, lime and fly ash proved to be beneficial for safe surface disposal of these wastes with minimal leaching of hazardous metals (Manjunatha and Sunil 2013). The application of activated carbon, biochar, bentonite, cement kiln dust, sugar beet factory lime, zeolite, etc., as low-cost amendments in contaminated soil helped in immobilization of toxic elements such as $\mathrm{Ni}$ and Zinc and reduced their phyto-availability (Kilpimaa et al. 2013; Xu et al. 2013; Ahmad et al. 2014; Belviso et al. 2014; Shaheen and Rinklebe 2015). It is indicated in the 
literature that lightweight sintered aggregates prepared by mixing sewage sludge and fly ash in definite weight ratio can be an environmentally friendly approach for disposal of these wastes with stabilization of heavy metals (Wei 2015). The disposal of fly ash in acidic environment with decreasing $\mathrm{pH}$ increased the leaching of major heavy metals and contaminated the ground water at the disposal site. Thus, the co-disposal of fly ash and brine may not be a suitable option from environmental point of view (Fatoba et al. 2015).

Besides, the disposal of these wastes in slurry form through high-concentration mode may result in lower energy consumption and reduced water consumption and hence improve upon pipe economics. The leaching of toxic elements can be minimized by transporting the ash slurry at high solids concentration as the production of leachate can be controlled by the evaporation of bleeding water (Iyer 2002). At higher solids concentration, the viscosity of the slurry increases and flow behaviour changes drastically affecting the rheological parameters. Literature reveals that the addition of some agents/surface-active reagents can modify the flow behaviour of fine-particulate ash slurry, resulting in reduction in viscosity (Vlasak and Chara 2007; Seshadri et al. 2008; Naik et al. 2011; Singh and Lal 2012; Kumar et al. 2013).

The objective of this study is to analyse the concentration of heavy metals $\mathrm{Cu}, \mathrm{Pb}, \mathrm{Ni}, \mathrm{Co}, \mathrm{Zn}, \mathrm{Cd}, \mathrm{Hg}$ and $\mathrm{As}$ in the two fly ash samples collected from JSPL, Raigarh and OPGC, Sambalpur, India, and to access the leaching characteristics of the ash samples in presence of some selective low-cost additives to inhibit the degree of contamination of these heavy metals. Further, the effect of these additives on rheological behaviour of the two ash samples was investigated and a comparative evaluation of the rheological parameters for the high-concentration ash slurry $\left(C_{\mathrm{W}}=60 \%\right)$ with the selective additives was carried out in order to reduce the pumping power and energy consumption during disposal of these huge wastes. The leaching characteristics of the ash samples were investigated with small dosage of the additives ( $1 \%$ of the total solids) over a period of 7 days at IMMT, Bhubaneswar, during November 11-17, 2014.

\section{Materials and methods}

\section{Characterization of fly ash samples}

Fly ash samples used for the leaching and rheological experiments were collected from two Indian thermal power plants, namely Jindal Steel and Power Limited, Raigarh, Chhattisgarh, and Odisha Power Generation Corporation, Jharsuguda, Odisha. The material density of the two ash samples was determined using standard specific gravity bottles following standard procedure. Ashes may be alkaline or acidic depending upon its elemental constituents. Aqueous suspension of the ash samples was prepared in distilled water medium for $\mathrm{pH}$ measurements following standard procedure. The instantaneous $\mathrm{pH}$ and the stabilized $\mathrm{pH}$ values after $5 \mathrm{~h}$ of mixing were determined using a standard $\mathrm{pH}$ meter. The particle size distribution of the fly ash samples was carried out using a Malvern particle size analyser. The chemical composition of the bulk ash samples was carried out by Philips PW2440 X-ray spectrometer. The visual observation indicated that JSPL fly ash was blackish grey and OPGC ash was light grey in colour. The physicochemical characteristics of the two fly ash samples are presented in Table 1.

\section{Determination of heavy metal in fly ash samples}

The heavy metals' concentration in JSPL and OPGC fly ash samples was determined by following the standard procedure; for this purpose, two nos. of Teflon beakers were cleaned by soap wash followed by nitric acid wash. Two grams of fly ash samples with $20 \mathrm{ml}$ of concentrated HF was poured into the Teflon beakers and mixed properly. The solution in both the beakers was intermittently stirred and heated for period of $2 \mathrm{~h}$ to completely evaporate the nitric acid from the solution. After completely drying off the samples, the residue was further leached in $10 \mathrm{ml}$ of $6 \mathrm{M} \mathrm{HCL}$ for $2 \mathrm{~h}$ and dried. Then $60 \mathrm{ml}$ of distilled water was added to both the beakers containing the solutions and again heated up to $15 \mathrm{~min}$. Then, the solutions were filtered into two conical flasks and the filtrate was taken for analysing the heavy metal concentration in fly ash samples. The liberated ionic species such as $\mathrm{Zn}, \mathrm{Cd}, \mathrm{Ni}, \mathrm{Pb}, \mathrm{Cu}$ and Co were determined by atomic absorption spectrophotometry (Make: SIMADJU, Model No: AA6300). The determination of As and $\mathrm{Hg}$ was carried out by incorporating hydrogen vapour generator (HUG) and mercury vapour generator (MUG) as extra attachments in atomic absorption spectrophotometry. The concentration of different heavy metals present in two different fly ash samples is presented in Table 2 .

\section{Batch leaching (7-day duration) of fly ash samples with selective additives}

In the present study, batch leaching procedure has been adopted to evaluate the effect of various low-cost selective additives on leaching characteristics of the two fly ash samples. Twenty-five grams of fly ash samples was suspended in $100 \mathrm{ml}$ deionized water in a 250-ml polyethylene bottle. The bottle was shaken five times daily using a vibrational bath shaker for a period of 7 days. A 
Table 1 Physicochemical characteristic of the two fly ash samples

\begin{tabular}{|c|c|c|}
\hline Parameters & $\begin{array}{l}\text { Sample } 1 \\
\text { (JSPL), SD }\end{array}$ & $\begin{array}{l}\text { Sample } 2 \\
\text { (OPGC), SD }\end{array}$ \\
\hline Instant $\mathrm{pH}$ of ash-water slurry in distilled water medium $\left(C_{\mathrm{W}}=60 \%\right)$ & $5.64, \pm 0.04$ & $4.67, \pm 0.06$ \\
\hline $\begin{array}{l}\mathrm{pH} \text { of ash-water slurry in distilled water medium after a mixing period } \\
\text { of } 5 \mathrm{~h}\left(C_{\mathrm{W}}=60 \%\right)\end{array}$ & $6.52, \pm 0.06$ & $4.73, \pm 0.04$ \\
\hline Material density, $\rho_{\mathrm{s}}\left(\mathrm{kg} / \mathrm{m}^{3}\right)$ & $3262, \pm 4.5$ & $2039, \pm 3.6$ \\
\hline Median particle size, $d_{50}(\mu \mathrm{m})$ & $25.2, \pm 0.4$ & $51.0, \pm 1.3$ \\
\hline Top size $(\mu \mathrm{m})$ & $633, \pm 3.06$ & $2000, \pm 5$ \\
\hline Maximum static settled concentration, $C_{\mathrm{W}-\max }(\mathrm{wt} \%)$ & $69.409, \pm 0.007$ & $66.85, \pm 0.1$ \\
\hline \multicolumn{3}{|l|}{ Chemical composition of fly ash samples } \\
\hline $\mathrm{SiO}_{2}$ & $51.9, \pm 0.9$ & $59.55, \pm 1.5$ \\
\hline $\mathrm{Al}_{2} \mathrm{O}_{3}$ & $35.03, \pm 0.95$ & $32.77, \pm 0.53$ \\
\hline $\mathrm{Fe}_{2} \mathrm{O}_{3}$ & $8.11, \pm 0.65$ & $3.39, \pm 0.03$ \\
\hline $\mathrm{P}_{2} \mathrm{O}_{5}$ & $0.008, \pm 0.003$ & $0.49, \pm 0.4$ \\
\hline $\mathrm{CaO}$ & $0.76, \pm 0.11$ & $0.59, \pm 0.3$ \\
\hline $\mathrm{MgO}$ & $0.078, \pm 0.008$ & $0.01, \pm 0.05$ \\
\hline $\mathrm{K}_{2} \mathrm{O}$ & $0.33, \pm 0.06$ & $0.85, \pm 0.02$ \\
\hline $\mathrm{Na}_{2} \mathrm{O}$ & $0.37, \pm 0.05$ & $0.092, \pm 0.004$ \\
\hline $\mathrm{SO}_{3}$ & $0.004, \pm 0.002$ & $0.018, \pm 0.006$ \\
\hline $\mathrm{TiO}_{2}$ & - & $1.66, \pm 0.08$ \\
\hline $\mathrm{BaO}$ & - & $0.03, \pm 0.03$ \\
\hline LOI & $3.41, \pm 0.04$ & $0.55, \pm 0.06$ \\
\hline
\end{tabular}

$S D$ standard deviation

\begin{tabular}{llll}
\hline S1. no. & $\begin{array}{l}\text { Parameters/ } \\
\text { component }\end{array}$ & $\begin{array}{l}\text { Concentration in JSPL } \\
\text { fly ash samples }(\mu \mathrm{g} / \mathrm{g}), \mathrm{SD}\end{array}$ & $\begin{array}{l}\text { Concentration in OPGC } \\
\text { fly ash samples }(\mu \mathrm{g} / \mathrm{g}), \mathrm{SD}\end{array}$ \\
\hline 1. & $\mathrm{Zn}$ & $165, \pm 4.5$ & $161, \pm 1$ \\
2. & $\mathrm{Cd}$ & $3.2, \pm 0.3$ & $10, \pm 0.7$ \\
3. & $\mathrm{Ni}$ & $62, \pm 2.5$ & $53, \pm 0.3$ \\
4. & $\mathrm{~Pb}$ & $120, \pm 2$ & $86, \pm 1.02$ \\
5. & $\mathrm{Cu}$ & $115, \pm 4.5$ & $45, \pm 1.01$ \\
6. & $\mathrm{Co}$ & $49, \pm 2.5$ & $14, \pm 0.8$ \\
7. & $\mathrm{As}$ & $2.6, \pm .52$ & $81, \pm 0.5$ \\
8. & $\mathrm{Hg}$ & $0.2, \pm 0.12$ & $0.18, \pm 0.05$ \\
\hline
\end{tabular}

$S D$ standard deviation

Table 2 Heavy metal concentrations in the ash samples $(\mu \mathrm{g} / \mathrm{g})$

\section{Rheological experiments}

shaking and was filtered through a $0.45-\mu \mathrm{m}$ membrane filter. The filtrate was analysed for heavy metals by atomic absorption spectrophotometer. By following the same procedure, another five sets of fly ash-aqueous suspensions were prepared with the addition of ( $1 \%$ of the total solids) selective additives for leaching studies. The additives used were sodium silicate $\left(\mathrm{Na}_{2} \mathrm{SiO}_{3} \cdot 5 \mathrm{H}_{2} \mathrm{O}\right)$, Reetha fruit (botanical name: Sapindus Mukorossi) extract, banana leaf extract, Aloe vera juice and activated carbon. Each experiment was repeated twice, and the average value of two sets of experiment was recorded for analysis.
The rheological measurements of the two fly ash samples were conducted using a HAAKE precision rheometer. The representative samples for the rheological tests were taken, and slurries at different weight concentrations were prepared with distilled water as medium. The viscosity and shear stress were measured under the controlling shear rate in the range of $0-300 \mathrm{~s}^{-1}$ for a period $1 \mathrm{~min}$. Steady state shear measurements were performed at room temperature of $30{ }^{\circ} \mathrm{C}$. The variation in temperature was $\pm 0.1{ }^{\circ} \mathrm{C}$ regulated through a constant temperature circulator bath 
connected to the rheometer. The reproducibility of the rheological measurements was ascertained by repeating the experiment twice at a specific slurry concentration. The results of the rheological experiments without additives for the two ash samples were recorded for analysis. By following the same procedure, rheological experiments were conducted with JSPL and OPGC fly ash samples with the addition of selective additives ( $1 \%$ of the total solids) such as sodium silicate, Reetha fruit extract, banana leaf extract, Aloe vera juice and activated carbon in the same range of slurry concentrations. The rheological parameters of the fly ash slurry affected by the addition of small dosages of selective additives are presented in Table 4.

\section{Results and discussion}

Results for heavy metal analysis of the two fly ash samples are presented in Table 2. It is seen from Table 2 that the concentration of $\mathrm{Pb}, \mathrm{Zn}, \mathrm{Cu}$ and $\mathrm{Ni}$ is higher as compared to the concentration of $\mathrm{Cd}, \mathrm{As}, \mathrm{Co}$ and $\mathrm{Hg}$ in both the fly ash samples. The discrepancy in concentration of the heavy metals present in the two fly ash samples may be explained as follows. The heavy metals such as $\mathrm{Pb}, \mathrm{Zn}, \mathrm{Cu}$ and $\mathrm{Ni}$ with lower molecular mass have a tendency to be carried out and precipitated with fly ash after combustion in boiler. In contrast, the elements such as $\mathrm{Cd}$, $\mathrm{As}$, $\mathrm{Co}$ and $\mathrm{Hg}$ with higher molecular mass settle rapidly with bottom ash after combustion. Similar type of analysis results has been reported in the literature (Sushil and Batra 2006; Lokeshappa et al. 2014).

\section{Characteristics of short-duration batch leaching with selective additives}

The results of short-duration batch leaching tests for the two fly ash samples are shown in Table 3. It is observed from Table 3 that after 7 days of aqueous leaching tests, the concentration of most of the heavy metals reduces except a few cases with the selective additives. Activated carbon, sodium silicate and Aloe vera juice influenced the most on leachability of heavy metals from the two fly ash samples. The addition of sodium silicate to the aqueous fly ash solution increases the $\mathrm{pH}$ value of the system due to the formation of $\mathrm{NaOH}$ through hydrolysis. The increase in $\mathrm{pH}$ of the solution probably helps most of the heavy metals to be trapped in the geopolymer matrix by physical encapsulation mechanism. In case of activated carbon, physical adsorption might be the principal mechanism for reducing the concentration of heavy metals. The other three leaf/fruit extracts which contain significant amount of polyhydroxy compound such as saponins, sterols might have bound the metal ions through their polar groups. The concentration of Co increased with the addition of $1 \%$ Aloe vera juice, banana leaf extract and Reetha fruit extract for both the fly ash samples. This may be due to high concentration of $\mathrm{Co}$

Table 3 Aqueous leaching test analysis of JSPL and OPGC fly ash samples with and without selective additives

\begin{tabular}{|c|c|c|c|c|c|c|c|}
\hline Sample name & $\begin{array}{l}\text { Heavy metal } \\
\text { concentration } \\
\text { of leached-out } \\
\text { liquor }(\mathrm{mg} / \mathrm{L})\end{array}$ & $\begin{array}{l}\text { No additives } \\
\text { (SD) }\end{array}$ & $\begin{array}{l}\text { Aloe vera } \\
\text { juice (SD) }\end{array}$ & $\begin{array}{l}\text { Banana leaf } \\
\text { extract (SD) }\end{array}$ & $\begin{array}{l}\text { Reetha fruit } \\
\text { extract (SD) }\end{array}$ & $\begin{array}{l}\text { Activated } \\
\text { carbon (SD) }\end{array}$ & $\begin{array}{l}\text { Sodium Silicate } \\
\mathrm{Na}_{2} \mathrm{SiO}_{3} \cdot 5 \mathrm{H}_{2} \mathrm{O} \\
\text { (SD) }\end{array}$ \\
\hline \multirow[t]{8}{*}{ JSPL fly ash } & $\mathrm{Cu}$ & $0.009, \pm 0.001$ & $0.001, \pm 0.001$ & $0.005, \pm 0.002$ & $\mathbf{0 . 0 1}, \pm 0.001$ & $0.001, \pm 0.003$ & $0.008, \pm 0.003$ \\
\hline & $\mathrm{Pb}$ & $0.042, \pm 0.007$ & $0.018, \pm 0.004$ & $0.009, \pm 0.004$ & $0.047, \pm 0.004$ & $0.018, \pm 0.007$ & $0.017, \pm 0.005$ \\
\hline & $\mathrm{Ni}$ & $0.017, \pm 0.008$ & $0.015, \pm 0.006$ & $0.006, \pm 0.003$ & $0.007, \pm 0.003$ & $0.004, \pm 0.001$ & $\mathbf{0 . 0 3 9}, \pm 0.004$ \\
\hline & $\mathrm{Co}$ & $0.043, \pm 0.01$ & 0.116, \pm 0.007 & $\mathbf{0 . 0 9 3}, \pm 0.008$ & $\mathbf{0 . 0 9 8}, \pm 0.012$ & $0.025, \pm 0.007$ & $0.026, \pm 0.009$ \\
\hline & $\mathrm{Zn}$ & $0.055, \pm 0.005$ & $0.002, \pm 0.002$ & $0.004, \pm 0.001$ & $0.005, \pm 0.001$ & $0.002, \pm 0.001$ & $0.009, \pm 0.0006$ \\
\hline & $\mathrm{Cd}$ & $0.002, \pm 0.006$ & $0.002, \pm 0.0001$ & $0.001, \pm 0.0005$ & $0.001 \pm 0.0001$ & $0.002, \pm 0.0001$ & $0.001, \pm 0.0001$ \\
\hline & $\mathrm{Hg}$ & $0.01, \pm 0.1$ & $0.012, \pm 0.005$ & $0.009, \pm 0.004$ & $0.009, \pm 0.004$ & $0.008, \pm 0.002$ & $0.007, \pm 0.005$ \\
\hline & As & $0.032, \pm 0.01$ & $0.008, \pm 0.002$ & $\mathbf{0 . 0 5 6}, \pm 0.004$ & $0.029, \pm 0.003$ & $0.015, \pm 0.003$ & $\mathbf{0 . 0 3 6}, \pm 0.003$ \\
\hline \multirow[t]{8}{*}{ OPGC fly ash } & $\mathrm{Cu}$ & $0.003, \pm 0.002$ & $0.001, \pm 0.0001$ & $0.001, \pm 0.0001$ & $0.003, \pm 0.002$ & $0.0003, \pm 0.00002$ & $0.002, \pm 0.0001$ \\
\hline & $\mathrm{Pb}$ & $0.03, \pm 0.006$ & $0.027, \pm 0.003$ & $0.006, \pm 0.0006$ & $\mathbf{0 . 0 3 2}, \pm 0.005$ & $0.013, \pm 0.005$ & $0.012, \pm 0.005$ \\
\hline & $\mathrm{Ni}$ & $0.015, \pm 0.004$ & $0.011, \pm 0.003$ & $0.005, \pm 0.004$ & $0.005, \pm 0.004$ & $0.004, \pm 0.001$ & $\mathbf{0 . 0 3 4}, \pm 0.004$ \\
\hline & Co & $0.012, \pm 0.003$ & $\mathbf{0 . 0 4 5}, \pm 0.005$ & $\mathbf{0 . 0 8 2}, \pm 0.005$ & $\mathbf{0 . 0 5 6}, \pm 0.005$ & $0.007, \pm 0.002$ & $0.007, \pm 0.002$ \\
\hline & $\mathrm{Zn}$ & $0.048, \pm 0.004$ & $0.022, \pm 0.003$ & $0.018, \pm 0.004$ & $0.021, \pm 0.005$ & $0.003, \pm 0.002$ & $0.008, \pm 0.002$ \\
\hline & $\mathrm{Cd}$ & $0.006, \pm 0.003$ & $0.003, \pm 0.002$ & $0.001, \pm 0.001$ & $0.001, \pm 0.001$ & $0.001, \pm 0.001$ & $0.003, \pm 0.002$ \\
\hline & $\mathrm{Hg}$ & $0.009, \pm 0.0006$ & $0.004, \pm 0.001$ & $0.004, \pm 0.001$ & $\mathbf{0 . 0 1 1}, \pm 0.001$ & $0.008, \pm 0.002$ & $0.006, \pm 0.003$ \\
\hline & As & $0.097, \pm 0.01$ & $0.042, \pm 0.005$ & $0.07, \pm 0.004$ & $0.054, \pm 0.004$ & $0.039, \pm 0.002$ & $\mathbf{0 . 1 1}, \pm 0.03$ \\
\hline
\end{tabular}

Bold values indicate higher concentration of heavy metals with the selected addtives than those of without addtives

$S D$ standard deviation 
(a)
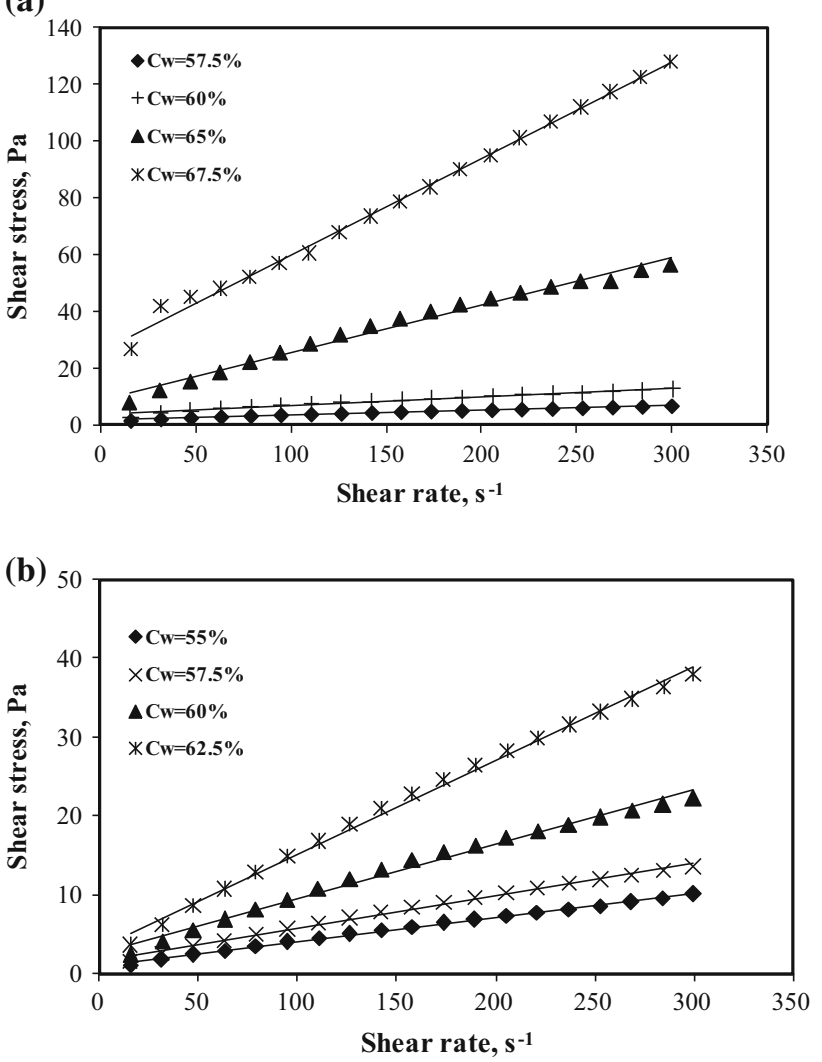

Fig. 1 a Rheogram of JSPL fly ash samples at different weight concentrations. b Rheogram of OPGC fly ash samples at different weight concentrations

in non-magnetic fraction of the ash samples, making it more mobile and unaffected by $\mathrm{pH}$ of aqueous ash solution with the addition of the aforementioned additives. Similarly, the concentration of $\mathrm{Ni}$ and $\mathrm{As}$ indicated an increasing trend with the addition of $1 \%$ sodium silicate for the two ash samples after seven days of aqueous leaching, which can be explained as follows. During combustion of coal, Ni may be present in the silicate and magnetic fraction of fly ash and the solubility of $\mathrm{Ni}$ is very much sensitive to $\mathrm{pH}$ of the system. The dosage of sodium silicate improves the $\mathrm{pH}$ of solution resulting in an increase in Ni concentration. Arsenic may be enriched on the surface of fly ash as sparingly soluble arsenate species and the dosage of sodium silicate additive mildly increase the alkalinity of the acidic aqueous ash samples with greater releases of As. Further, sodium silicate behaves as a sequestering agent which increases the solubility of the metal ions and might be replacing the $\mathrm{Ni}$ and As to form compounds, releasing free $\mathrm{Ni}$ and As ions. A minute or no increase in concentration of $\mathrm{Cu}, \mathrm{Pb}$ and $\mathrm{Hg}$ was observed with the addition of Reetha fruit extract for the two fly ash samples.

\section{Rheological characteristics of the two fly ash samples}

From the maximum static settled concentration tests, the $C_{\mathrm{W}-\max }$ values obtained for JSPL and OPGC ash samples were found to be 69.409 and $66.85 \%$ by weight, respectively (Table 1). The rheological data of both the ash slurry samples in specific concentration ranges under good flowable conditions were considered for the shear stressshear rate plots. The shear stress $(\tau)$ and shear rate $(\dot{\gamma})$ data obtained for the two fly ash samples in the studied range of slurry concentrations were plotted and are presented in Fig. 1a, b.

It is seen that the variation of the shear stress with shear rate at all concentrations followed a straight line behaviour with $R^{2}$ values in the range of $0.984-0.999$. Thus, the Bingham-plastic model that fitted to the rheological data can be expressed as:

$\tau=\tau_{y}+_{p} \dot{\gamma}$

where $\tau$ (pa) is the shear stress, $\tau_{y}(\mathrm{~Pa})$ is the yield stress, $\dot{\gamma}$ $\left(\mathrm{s}^{-1}\right)$ is the shear rate, $p$ (Pas) is the plastic viscosity. The flow behaviour of the ash samples is characterized by the existence of a yield stress $\left(\tau_{y}\right)$, and the flow pattern is nonNewtonian at these solid concentrations, which is observed from the shape of the rheograms $\tau-\dot{\gamma}$ in Fig. 1. It is also observed from Fig. 1 that the shear stress values for JSPL ash samples indicated higher values than for OPGC ash samples in the studied range of shear rates. This may be due to the difference in particle size distribution of both the ash samples. JSPL ash samples were finer in nature and therefore incurred higher shear stress values as compared to OPGC ash samples in the studied range of shear rates and slurry concentrations.

\section{Influence of selective additives on rheological parameters for the fly ash samples}

Table 4 shows the effect of addition of the five selective additives ( $1 \%$ of the total solids) on the yield stress and Bingham-plastic viscosity at a slurry concentration of $60 \%$ by weight.

From the table, it is observed that the addition of the five selective additives influenced both the yield stress and plastic viscosity of the two ash slurry samples. The percentage reduction in yield stress was in the range of 12.62-56.31 and $24.18-45.91 \%$ for JSPL and OPGC fly ash samples, respectively. The addition of sodium silicate significantly reduced the yield stress values of the two fly ash samples and was found to be 56.31 and $45.91 \%$ for JSPL and OPGC fly ash samples, respectively. It is also observed from Table 4 that the Bingham-plastic viscosity value decreased with the addition of $1 \%$ of the five 
Table 4 Rheological properties of fly ash samples with and without selective additives at $C_{\mathrm{W}}=60 \%$

\begin{tabular}{|c|c|c|c|c|}
\hline \multirow[t]{2}{*}{ Name of selective additive } & \multicolumn{2}{|c|}{ JSPL fly ash samples } & \multicolumn{2}{|c|}{ OPGC fly ash samples } \\
\hline & $\begin{array}{l}\text { Yield stress, } \\
\tau_{y}(\mathrm{~Pa}), \mathrm{SD}\end{array}$ & $\begin{array}{l}\text { Slurry viscosity, } \\
\eta_{p}(\mathrm{~Pa}), \mathrm{SD}\end{array}$ & $\begin{array}{l}\text { Yield stress, } \\
\tau_{y}(\mathrm{~Pa}), \mathrm{SD}\end{array}$ & $\begin{array}{l}\text { Slurry viscosity, } \\
\eta_{p}(\mathrm{~Pa}), \mathrm{SD}\end{array}$ \\
\hline Without additives & $3.637, \pm 0.003$ & $0.031, \pm 0.003$ & $2.646, \pm 0.02$ & $0.068, \pm 0.002$ \\
\hline With $1 \%$ Aloe vera juice & $3.178, \pm 0.004$ & $0.026, \pm 0.004$ & $1.842, \pm 0.006$ & $0.057, \pm 0.002$ \\
\hline With $1 \%$ banana leaf extract & $3.078, \pm 0.004$ & $0.024, \pm 0.005$ & $1.74, \pm 0.04$ & $0.06, \pm 0.003$ \\
\hline With $1 \%$ Reetha fruit extract & $3.111, \pm 0.003$ & $0.025, \pm 0.005$ & $2.006, \pm 0.003$ & $0.057, \pm 0.002$ \\
\hline With $1 \%$ activated carbon & $3.119, \pm 3.003$ & $0.027, \pm 0.006$ & $1.853, \pm 0.005$ & $0.058, \pm 0.03$ \\
\hline With $1 \%$ sodium silicate $\left(\mathrm{Na}_{2} \mathrm{SiO}_{3} \cdot 5 \mathrm{H}_{2} \mathrm{O}\right)$ & $1.589, \pm 0.003$ & $0.03, \pm 0.02$ & $1.431, \pm 0.003$ & $0.066, \pm 0.03$ \\
\hline
\end{tabular}

$S D$ standard deviation

selective additives for the two ash samples. The percentage of reduction in Bingham-plastic viscosity was in the range of 3.22-22.58 and 2.94-16.2\% for JSPL and OPGC fly ash samples, respectively. The addition of banana leaf extract indicated a maximum reduction in Bingham-plastic viscosity value $(22.58 \%)$ with JSPL fly ash samples, whereas Aloe vera juice indicated a maximum reduction of $16.2 \%$ in Bingham-plastic viscosity for OPGC fly ash samples.
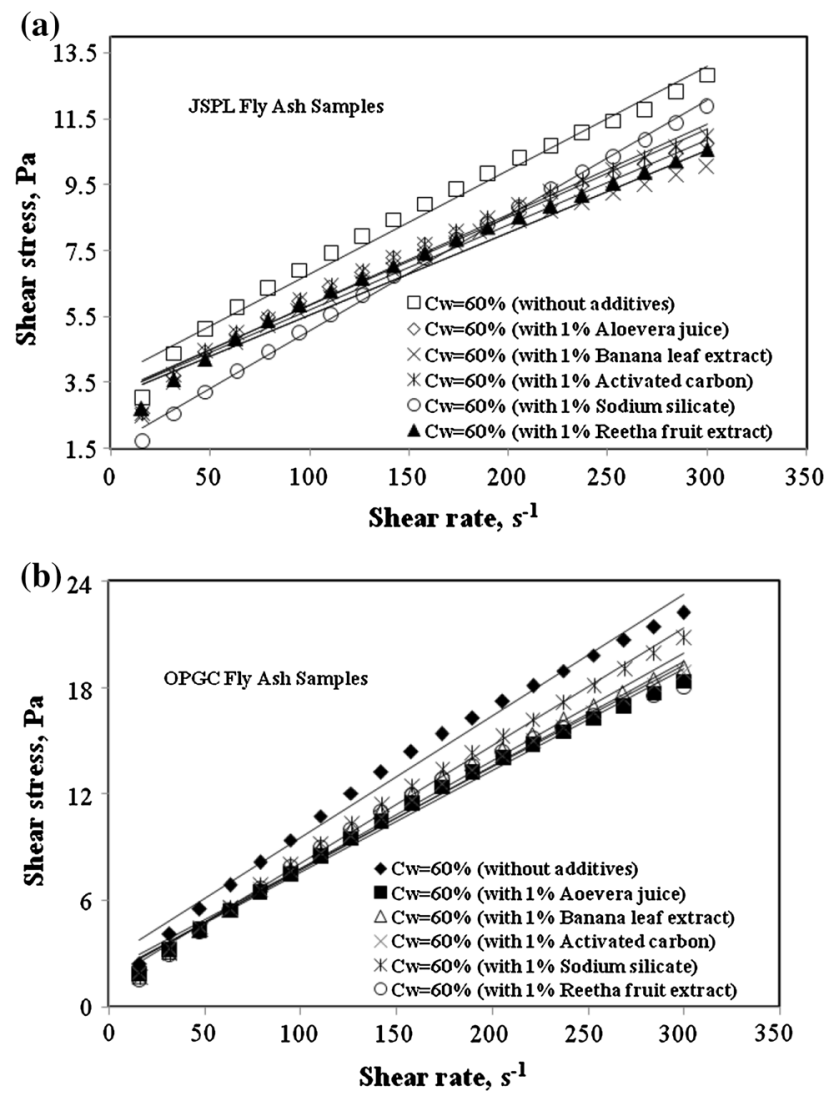

Fig. 2 a Effect of selective additives on rheological behaviour of JSPL fly ash slurry samples at $C_{\mathrm{W}}=60 \%$. b Effect of selective additives on rheological behaviour of OPGC fly ash slurry samples at $C_{\mathrm{W}}=60 \%$
The rheograms of both the ash samples with the five selective additives are presented in Fig. 2a, b. As indicated from Fig. 2a, b, it is observed that the dosage of sodium silicate incurred higher shear stress values at high shear rates as compared to other four additives. On the other hand, the reduction in yield stress for both the ash samples with sodium silicate is quite significant, which may have beneficial effects for transporting the ash slurry in pipelines incurring less pumping energy.

\section{Conclusion}

The results of the present study reveals that the leaching of heavy metals can be minimized at the disposal sites by appropriate dosage of selective low-cost additives to the fly ash slurry. The short-duration (7 days) batch aqueous leaching tests indicated that the concentration of most of the heavy metals reduces in the leached-out liquor with the addition of small dosage of sodium silicate $\left(\mathrm{Na}_{2} \mathrm{SiO}_{3}\right.$ $5 \mathrm{H}_{2} \mathrm{O}$ ), Reetha fruit (botanical name: Sapindus Mukorossi) extract, banana leaf extract, Aloe vera juice and activated carbon as selective additives. The flow behaviour of the two fly ash samples was characterized by Bingham-plastic model at high solids concentration (55-67.5\% by weight). The environmental risks associated with the conventional dilute ash slurry disposal system can be replaced by highconcentration (dense phase) ash slurry disposal system where the selective additives can significantly modify the rheological properties of the high-concentration ash slurry for economic disposal. However, long-duration (8-12 weeks) continuous leaching studies with optimum dosage of selective additives are required to be carried out to predict the relative rates of release of these heavy metals and to apply the appropriate and proper dosage of selective additives for stabilization of heavy metals in the long run.

Acknowledgments The authors are thankful to Director, CSIR-Institute of Minerals and Materials Technology, for giving permission 
to publish the paper. The partial funding by M/s Jindal Steel \& Power Limited, Raigarh, India, for the present investigation is acknowledged.

\section{References}

Ahmad M, Rajapaksha AU, Lim JE, Zhang M, Bolan N, Mohan D (2014) Biochar as a sorbent for contaminant management in soil and water: a review. Chemosphere 99:19-33

Belviso C, Cavalcante F, Spartaco DiG, Palma A, Ragone P, Fiore S (2014) Mobility of trace elements in fly ash and in zeolitised coal fly ash. Fuel 144:369-379

Chen H, Wang X, Zhong L, Xu S, Xiao T (2014) Comparison of Mercury emission in USA \& China-the way of effective control of $\mathrm{Hg}$ from the power plant. Int J Waste Resour 4(2):138

Dawle N, Khadse SK, Patil PV, Panhekar D (2014) Evolution of fly ash management strategies - a review of selected value-added fly ash utilization approaches. Int J Adv Res 2(2):847-853

Fatoba OO, Petrik LF, Akinyeye RO, Gitari WM, Iwuoha EI (2015) Long-term brine impacted fly ash. Part 1: chemical and mineralogical composition of the ash residues. Int $\mathrm{J}$ Environ Sci Technol 12:551-562

Iyer R (2002) The surface chemistry of leaching of coal fly ash. J Hazard Mater B93:321-329

Kilpimaa S, Kuokkanen T, Lassi U (2013) Characterization and utilization potential of wood ash from combustion process and carbon residue from gasification process. BioResources 8(1):1011-1027

Kosson DS, Garrabrants AC, Delapp R, Sloot HAV (2014) pHdependent leaching of constituents of potential concern from concrete materials containing coal combustion fly ash. Chemosphere 103:140-147

Krgovic R, Trifkovic J, Opsenica DM, Manojlovic D, Mutic J (2015) Leaching of major and minor elements during transport and storage of coal ash obtained in power plant. Sci World J 2014:1-8

Kumar S, Mohapatra SK, Gandhi BK (2013) Effect of addition of fly ash and drag reducing on the rheological properties of bottom ash. Int J Mech Mater Eng 8(1):1-8

Lokeshappa B, Dikshit AK, Luo Y (2014) Assessing bioaccessible fractions of arsenic, chromium, lead, selenium and zinck in coal fly ashes. Int J Environ Sci Technol 11:1601-1610
Manjunatha LS, Sunil BM (2013) Stabilization/solidification of iron ore mine tailings using cement, lime and fly ash. Int J Res Eng Technol 2(12):625-635

Naik HK, Mishra MK, Rao KUM (2011) Influence of chemical reagents on rheological properties of fly ash-water slurry at varying temperature environment. Coal Combust Gasif Prod 3:83-93

Rind AM, Mastoi GM, Quarishi MA, Samoo F (2014) Analysis of metal content and physical parameters of bottom ash from a furnace oil based power plant Jamshoro Sindh, Pakistan. Int J Sci Environ Technol 3(2):434-439

Senapati PK, Mohapatra R, Pani GK, Mishra BK (2012) Studies on rheological and leaching characteristics of heavy metals through selective additive in high concentration ash slurry. J Hazard Mater 229-230:390-397

Seshadri V, Singh SN, Jain KK, Verma AK (2008) Effect of additive on head loss in the high concentration slurry disposal of fly ash. J Inst Eng (India) MC 89:3-10

Shaheen SM, Rinklebe J (2015) Impact of emerging and low cost alternative amendments on the (im)mobilization and phytoavailability of $\mathrm{Cd}$ and $\mathrm{Pb}$ in a contaminated floodplain soil. Ecol Eng 74:319-326

Singh K, Lal K (2012) Effect of cetylpyridinium chloride, Triton $\mathrm{x}-100$ and sodium dodecyl sulfate on rheology of fly ash slurry. Int J Sci Res Publ 2(8):1-5

Singh RK, Gupta NC, Guha BK (2014) Assessment of ground water contamination for heavy metals in the proximity of ash ponds. Pollution 75:28016-28019

Sushil S, Batra VS (2006) Analysis of fly ash heavy metal content and disposal in three thermal power plants in India. Fuel 85:2676-2679

Vlasak P, Chara, Z (2007) Flow behaviour and drag reduction of fluidic ash-water slurries. In: Proceedings of the 17th international conference on hydraulic transport of solids, Hydrotransport-17, BHRA, The Southern African Institute of Mining and Metallurgy, pp 39-55

Wei N (2015) Leachability of heavy metals from lightweight aggregates made with sewage sludge and municipal solid waste incineration fly ash. Int $\mathrm{J}$ Environ Res Public Health 12:4992-5005

Xu W, Wang H, Zhu T, Kuang J, Jing P (2013) Mercury removal from coal combustion flue gas by modified fly ash. J Environ Sci 25:393-398 